\title{
Energy deposit by a xenon flash lamp illuminator dedicated to photothermal IR thermography: calculations and measurements
}

by J.L. BEAUDOIN $\left({ }^{\star}\right)$, J-F. HENRY $\left(^{\star \star}\right)$, E. MERIENNE( $\left.{ }^{*}\right)$ and R. DANJOUX $\left(^{* *}\right)$, P. EGEE( $\left.{ }^{* * *}\right)$, P. $\operatorname{COSTE}\left({ }^{* * *}\right)$

(") Université de Reims Champagne Ardenne, UFR Sciences, GRSM - LEO, BP 347, 51062 Reims Cedex.

(**) MECICA, 3, rue du Val Clair, ZI Pompelle, 51100 Reims

$\left(^{\star * *}\right)$ CEA - CESTA, Le Barp

\begin{abstract}
. calculations and by experimental measurements.

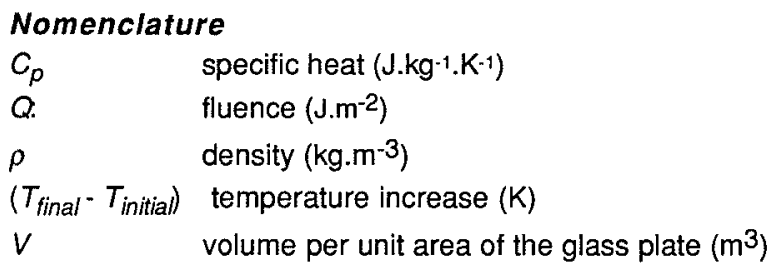

This communication deals with Non Destructive Evaluation of materials or structures via the measurement of their (thermal) impulse response function. The excitation is produced by a short and intense light pulse from xenon flash lamps. The repartition of the energy deposited over the object surface must be known qualitatively as well as quantitatively. A glass sheet is used as a calibration standard, the measurement of the heating beeing made by infared thermography. The various possible configurations are discussed. The validation of the procedure is established by a priori

\section{Introduction}

Thermal transients yield information about the thermophysical and / or structural properties of objects, thus providing the Non Destructive Testing community some new efficient tools. Amongst these, photothermal methods make use of light beams to force the object into a non-steady thermal state. One family of methods uses periodically modulated light beams, another one uses intense short flashes of light. In both cases, the thermal evolution of the object under investigation may be efficiently monitored by I.R radiometry : this is the so-called Photothermal Radiometry or P.T.R. Yu.Popov [1], and C.Martin [2], for example, have proposed to make use of an I.R thermography scanner to monitor the thermal behaviour of the samples. The advantage is that a whole area of the object is inspected at a glance, provided that the exciting beam is spread all over this area. Since these pioneering works, a lot of communications have been devoted to Photothermal Thermography (see for example: [3] to [6]).

A few equipments are now commercially available. Some of us (J.L.B., E.M., R.D.) have previously described [7] one of them, MECIR, (elaborated with the financial support of the French Ministery of Research and Technology). MECIR utilizes four powerful xenon flashlamps; whereas others utilize tungsten halogen lamps or short 1.R emitters, associated with mechanical shutters. 


\section{http://dx.doi.org/10.21611/qirt.1992.038}

Whatever the light source, it is highly desirable for several reasons to have a good knowledge, qualitatively and quantitatively, of the energy density (or fluence) $Q$ (J.m-2) deposited on the surface of the object:

- as a help in the design of the illuminator, in order to achieve a good uniformity of the excitation;

- for a quantitative exploitation of the measurements, and particularly in order to calculate the maximum temperature reached by the surface of the object, and thus to be able to avoid pyrolisis of this surface;

- periodic calibration of the illuminator is necessary to follow the effect of the lamps aging.

This paper proposes a rather simple calibration method together with a comparison of the experimental results to a priori calculations.

\section{Principle of operation}

A plane sheet of ordinary (window) glass is painted black on one of its face in order to be highly absorbing at the exciting wavelengths. This plate is exposed to the flash of light just in the same manner as for routine N.D.T. Glass has been chosen for several reasons:

- this material is cheap and readily available in quantities;

- in this kind of situation, its thermal behaviour is slow, which simplifies the measurement of Tinai,

- its thermo-physical properties can be reasonably assumed to be reproducible and stable in time; they can be measured with a good accuracy by usual methods;

- its I.R emissivity is high ( 0.9 in the $8-12 \mu \mathrm{m}$ range, and 0.96 in the $4.9-5.5 \mu \mathrm{m}$ range).

\subsection{Theoretical approach}

The flash of light is heat-converted on the black surface. The thermal transient behaviours of the (exposed) front surface and of the (unexposed) back surface are well known. Figure 1 shows the result of a priori calculations, carried out in the 1-D approximation by the finite difference method. The parameters used in the calculation have the following values:

$\begin{array}{llc} & \text { Glass } & \text { Black paint coating } \\ \text { Thickness (m) } & 0.003 & 50.10^{-6} \\ \text { Specific heat }\left(\mathrm{J} . \mathrm{kg}^{-1} . \mathrm{K}^{-1}\right) & 840 & 1000 \\ \text { Density }\left(\mathrm{kg} \cdot \mathrm{m}^{-3}\right) & 2530 & 2000 \\ \text { Thermal conductivity }\left(\mathrm{W} . \mathrm{K}^{-1} . \mathrm{m}^{-1}\right) & 0.81 & 1 \\ \text { Surface exch. coeff.(W.m-2.K-1) } & 8.5 & 8.5 \\ \text { Fluence (J.m-2) } & & 20000\end{array}$

After about $15 \mathrm{~s}$, the plate has become thoroughly isothermal at a temperature $T_{\text {final }}$. For a quick evaluation of the fluence $Q$, one can neglect surface losses and use a quite basic formula:

$$
Q=\left(T_{\text {final }}-T_{\text {initial }}\right) \rho C_{p} V
$$

where $V$ is the volume per unit area of the calibration plate. This simplified procedure leads to a slight $(<3 \%)$ underestimation of $Q$. A more accurate evaluation can be obtained by comparison with the theoretical calculation.

\subsection{Physical hypothesis}

Several hypotheses are used in this procedure, which have to be strengthened by theoretical considerations and/or experimental measurements. 
- Heat transfer is essentially uni-directional along the normal to the plate: this assumption is usual when the lateral dimensions are of one order magnitude higher than the thickness. For further safety, we have included, in the calibration procedure, the calculation of the thermal diffusivity all over the surface according to the identification scheme proposed by A. Degiovanni [8]. Local anomalies, if any, should raise some doubt about the 1-D approximation. This has never been observed, except at the very edges of the plate.

- The thermal contact resistance between the paint coating and the glass has neglectible effects; as long as the painting is adherent to the glass, this hypothetical resistance is small compared to the surface resistance $\left(\sim 0,1 \mathrm{~m}^{2}, \mathrm{~K} . \mathrm{W}-1\right)$.

- The paint thickness has neglectible effect: we have performed measurements with several glass plates covered with coating thicknesses ranging from 2 to $13.10^{-2} \mathrm{~mm}$ : as it was theoretically predictable, no difference was observed in the experimental $Q$ maps.

\section{Experimental procedure}

\subsection{Description of the experimental device}

The illuminator consists of four linear xenon flashlamps disposed at the four sides of a square. The tubes are $30 \mathrm{~cm}$ long. A reflector made of hammered reflecting aluminium (elephant skin) is disposed, so as to limit the light losses. Four separate capacitor banks are used; they can deliver up to $5 \mathrm{~kJ}$ to each tube. The flash duration is $8 \mathrm{~ms}$. The infrared thermography equipment consists in a $880 \mathrm{CV}$ AGEMA system ( 8 to $13 \mu \mathrm{m}$ range) and a numerical data acquisition and processing system (SAFIR, from L.E.O.-MECICA). The calibration glass plate is disposed parallel to the flashes at a distance of $20 \mathrm{~cm}$. The camera equipped with a $20^{\circ}$ lens is located $105 \mathrm{~cm}$ away from the glass plate so that the field of view is $30 \times 30 \mathrm{~cm}^{2}$.

\subsection{Calibration procedure}

Four configurations are possible according to the respective position of the black painting, the flashes and the IR camera. We report here the measurements carried out according to two of them presented on figure 2. The two others, where the exciting light has to travel through the glass before reaching the black paint, can be used as well. In these two latter configurations, volumic absorption occurs within the glass plate during the flash duration.

We checked that the temperature $T_{\text {final }}$ had the same value (within $\pm 0.1 \mathrm{~K}$ ) when measured either in the reflection or in the transmission mode. In this latter configuration, the IR camera sees its own image, as reflected by the air-glass interface. This pattern nearly completely disappears after substraction of the reference image (see figure $A)^{*}$.

The calibration procedure is as follows:

- four thermograms are captured just before the ignition of the flashes; after averaging they will provide a reference image;

- the transitory behaviour of the sample is measured every $200 \mathrm{~ms}$ during $15 \mathrm{~s}$;

- the series of thermograms are then processed in order to derive successively:

- the diffusivity at given locations (this step could be short-circuited),

- the values of the fluence $Q$ at every pixel of the surface,

- a fluence image that can be processed by the SAFIR software instead of thermograms. 


\subsection{Experimental results}

The electric energy stored in the four capacitor banks was adjusted at its maximum value i.e. $20 \mathrm{~kJ}$. At the center of the plate, the observed temperature difference $\left(T_{\text {final }}{ }^{-}\right.$ $\left.T_{\text {initial }}\right)$ reaches $(3,71 \pm 0,06) \mathrm{K}$. The value of the fluence $Q$, averaged over the $30 \times 30 \mathrm{~cm}^{2}$ area, is $22,200 \mathrm{~J} \mathrm{~m}^{2}$. The homogeneity of the energy deposit can be characterized by the value of the standard deviation measured on a given fluence map, which is nearly $5 \%$ of the average $Q$ value. The homogeneity of the energy deposit is thus quite satisfactory. The same series of experiments yields a value of the glass thermal diffusivity of $(6.00 \pm 0,15)$ $m^{2} \cdot s^{-1}$.

The short term reproducibility shows a standard deviation of $80 \mathrm{J.m}-2$. The long-term reproducibility of the experiment, including the influence of every experimental parameters, is the same.

\subsection{Non-plane objects}

It may be useful to evaluate the energy deposit on non-plane objects. Calculations may be used for this purpose. An alternative solution is to proceed experimentally, in which case rigid glass is no longer appropriate. We have made a few measurements using a thin $(2 \mathrm{~mm})$ black flexible Viton sheet. The thermal capacity of the Viton appeared to be about 0.9 times that of glass. Though the long term stability of Viton is somewhat questionable, it may be easily compared to glass.

\section{Theoretical calculation of the fluence repartition}

The arrangement of the flash-lamps in a square shape was first deduced from test calculation [9]. In a first approach, each tube was assimilated to a straight segment with isotropic emission. We then used a more realistic expression for the directional intensity per length unit $\left(W \operatorname{Std}^{-1} \mathrm{~m}^{-1}\right)[10]$ :

$$
I(\theta)=\frac{2 I_{0} \cos \theta}{1+\cos ^{2} \theta}
$$

where $\theta$ is the angle between the direction of emission and the axis of the flash lamp. One can see on figure $B$ such a fluence map calculated over a $40 \times 40 \mathrm{~cm}^{2}$ area, located 20 $\mathrm{cm}$ away from the flash lamps. The conversion efficiency, from electric to radiant energy, was assumed to be $50 \%$.

This simple model has proved to be quite helpful for the design of the illuminator. However it does not take into account the effect of the reflector. Thus, in order to compare experimental measurements to theoretical calculations, we had to mask the reflector. The results (see figure $A$ ) confirm the uniformity of the fluence. However, it appears that the value of the conversion efficiency was over-estimated: the true value may be approximately $30 \%$. This rather low value is due to the long (\#8 ms) duration time of the flash which implies lower values of the current density of discharge.

\section{Conclusion}

This calibration procedure is now routinely used in our respective laboratories. Although it is not a genuine metrologic grade, it has proved to be quite efficient and easy to process.

\section{Acknowledgement}

The authors gratefully acknowledge I.FOSSE, P.COTTEN, G.PIERRET and Y.BERRE for their collaboration. 


\section{REFERENCES}

[1] POPOV (Yu.A.) et al. .Sov. Journ. of non destructive testing, 13, 1977, p. 411-415.

[2] MARTIN (C.).-Contribution à l'utilisation de la thermographie infrarouge pour la mesure de flux, de températures et de divers paramètres. Thèse Doctorat ès Sciences, Université de Limoges, nov. 1978.

[3] BEAUDOIN (J.L.), DANJOUX (R), MERIENNE (E.) and EGEE (M).-Time resolved stimulated IR thermography applied to the subsurface control of materials. 4th int. topical meet. on photoacoustic thermal and related sciences, Montreal, Aug 4-8, 1985.

[4] BALAGEAS (D.L.), DEOM (A.A.) and BOSCHER (D.M.). Characterization and nondestructive testing of carbon-epoxy composites by a pulsed photothermal method. Materials evaluation, 4,1987 , p. 461-465.

[5] Thermosense, series of proceed. of Internat. conf. on Thermal sensing and Imaging diagnostic applications, SPIE, Washington, USA.

[6] Proceed. of the Internat. topical meetings on Photothermal and Photoacoustical phenomena, Heidelberg, July 27-30, 1987.

[7] DANJOUX (R.), BEAUDOIN (J.L.), MERIENNE (E.), EGEE (M.) and TRETOUT (H.).$M E C I R$, a new apparatus for the control of materials by infrared thermography. Infrared technology \& applicat. London, june 26-28, 1990, p.56C-59C.

[8] DEGIOVANNI (A.).-Contribution à l'étude de la diffusivité thermique. Thèse Doctorat ès Sciences, Université Claude Bernard de Lyon, juin 1975.

[9] BEAUDOIN (J.L.) et DANJOUX (R.).-Caractérisation $x-y-z$ de matériaux minces par thermographie infrarouge. Journ. CND APEND-SITEF, Toulouse, sept.1987.

[10] Introduction to flash lamps. ILC technic. bull. \#1

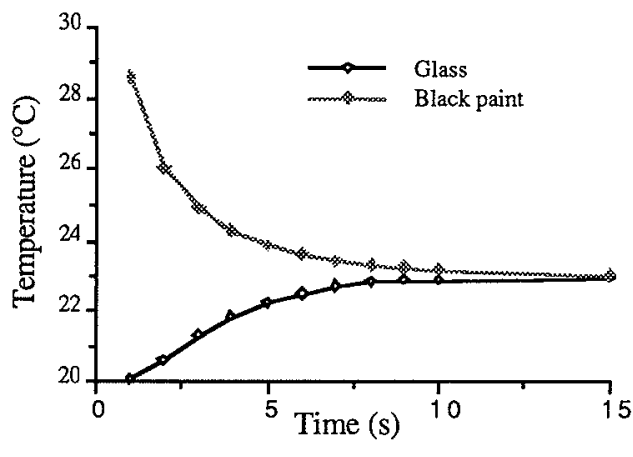

Fig.1.-Temperature versus time for the two faces of the painted glass plate; $8 \mathrm{~ms}$ flash lllumination.

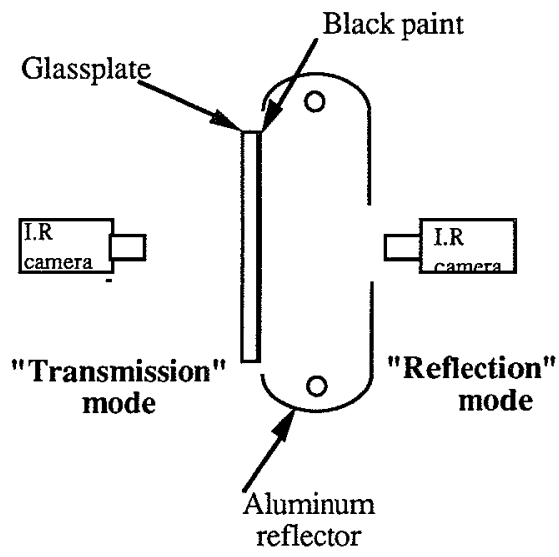

Fig.2.-Experimental set-up. 
http://dx.doi.org/10.21611/qirt.1992.038 
http://dx.doi.org/10.21611/qirt.1992.038

Inversion procedures 
http://dx.doi.org/10.21611/qirt.1992.038 